\title{
Tetrandrine prevents multidrug resistance in the osteosarcoma cell line, U-2OS, by preventing Pgp overexpression through the inhibition of NF- $\mathrm{KB}$ signaling
}

\author{
YANDONG LU ${ }^{1 *}$, FANGGUO LI ${ }^{1 *}$, TAO XU ${ }^{2}$ and JIE SUN ${ }^{1}$ \\ ${ }^{1}$ Department of Orthopaedic Traumatology, Tianjin Hospital, Hexi, Tianjin 300211; \\ ${ }^{2}$ Department of Orthopaedics, Jixian People's Hospital, Jixian, Tianjin 301900, P.R. China
}

Received November 9, 2015; Accepted January 16, 2017

DOI: $10.3892 /$ ijmm.2017.2895

\begin{abstract}
The development of multidrug resistance (MDR) remains a major limitation to successful chemotherapy in osteosarcoma. Preventing the introduction of MDR has been a research hotspot in clinical and investigational oncology. The aim of this study was to evaluate the preventive effects of tetrandrine (TET) against MDR in osteosarcoma. For this purpose, U-2OS human osteosarcoma cells were treated with paclitaxel alone or a combination of paclitaxel with TET. The cells treated with paclitaxel alone eventually acquired MDR along with the overexpression of and highly activated P-glycoprotein (Pgp), while the cells treated with the paclitaxelTET combination were sensitive to chemotherapeutic drugs and expressed decreased levels of Pgp and less Pgp activity. The promoter activities of MDR gene 1 (MDR1) and nuclear factor $(\mathrm{NF})-\kappa \mathrm{B}$, and the expression levels of NF- $\kappa \mathrm{B}$ and $\mathrm{p}-\mathrm{I} \kappa \mathrm{B}-\alpha$ were all enhanced in the cells cultured with paclitaxel alone. $\mathrm{NF}-\kappa \mathrm{B}$ DNA-binding activity and the binding ability of NF- $\mathrm{B}$ to the MDR1 promoter were also enhanced in the cells cultured with paclitaxel alone compared to the control cells. However, the expression and activity of NF- $\mathrm{B}$ were significantly decreased in the paclitaxel-TET combination-treated group as compared with the cells treated with paclitaxel alone. On the whole, our findings suggest that TET prevents paclitaxel-induced MDR by inhibiting Pgp overexpression through a mechanism that may involve the inhibition of NF- $\mathrm{BB}$ signaling in osteosarcoma.
\end{abstract}

\section{Introduction}

Osteosarcoma, one of the malignant bone tumors, predominantly occurs in children and adolescents (1-3). Currently,

Correspondence to: Jie Sun, Department of Orthopaedic Traumatology, Tianjin Hospital, 406 Jiefang South Road, Hexi, Tianjin 300211, P.R. China

E-mail: sunjiecntj@163.com

*Contributed equally

Key words: osteosarcoma, tetrandrine, multidrug resistance, $\mathrm{P}$-glycoprotein, nuclear factor- $\kappa \mathrm{B}$ signaling pathway the treatment for osteosarcoma mainly includes surgery and combination chemotherapy $(4,5)$. Multidrug resistance (MDR) is a formidable obstacle of chemotherapy in the treatment of osteosarcoma (6-8). Tumor cells can develop resistance to a wide variety of anticancer drugs, whose structure and function are usually unrelated, thus limiting the curative effects of chemotherapeutic drugs $(9,10)$. Therefore, the understanding of the pathological mechanisms of MDR is of great importance for developing effective therapies for osteosarcoma.

It has been reported that there are several mechanisms responsible for osteosarcoma becoming resistant to chemotherapeutic agents (6). One mechanism is the overexpression of ATP-binding cassette (ABC) transporters in cells which develop MDR, which causes reduced drug uptake and enhanced drug efflux (11-13). P-glycoprotein (Pgp), one of the most important ABC transporters, is encoded by MDR gene 1 (MDR1) (14). Pgp overexpression has been detected in multiple osteosarcoma cell lines with MDR and residual tumor cells in post-chemotherapy patients (14-17). Numerous drugs in osteosarcoma chemotherapy are substrates of Pgp, including doxorubicin, paclitaxel, vinblastine, vincristine and etoposide (18).

Pgp-mediated resistance to drugs can be reversed by inhibiting MDR1 drug pump function or by preventing MDR1 expression (11). A number of studies have been carried out on Pgp-mediated MDR. Various Pgp inhibitors have been developed, such as verapamil, PSC833, VX-710 and XR9576 (19), and curcumin has also been shown to inhibit Pgp (20). Over the past decade, preventing the initiation of MDR following chemotherapy has gained much attention (21-24). A variety of drugs, including verapamil, CsA, P85 and LGD1069 have been found to be preventers, averting the emergence of MDR $(21,22,24,25)$. Although clinical trials examining these preventers have been initiated, notable therapeutic results have not been acquired in these trials (26-29). Thus, exploring more potent and selective MDR preventers is of utmost importance.

Tetrandrine (TET), a bis-benzylisoquinoline alkaloid compound, was isolated from the root of Stephania tetrandra. TET is utilized as an anti-rheumatic, anti-inflammatory and anti-hypertensive agent with low toxicity in traditional Chinese medicine (30). Moreover, TET exhibits antitumor activity in both tumor cells and animal models (31-34). It has been reported that TET treatment can cause the notable 
downregulation of Pgp expression, which significantly reverses drug resistance in leukemia cells (35). Furthermore, TET has the ability to stimulate Pgp ATPase activity, thereby reversing Pgp-mediated MDR in cancer cells (36). Additionally, studies have demonstrated that TET can inhibit the development of MDR by preventing Pgp overexpression in the leukemia cell line, K562 (37). However, whether TET has the ability to prevent the enmergence of MDR in osteosarcoma has yet to be determined.

In the present study, we evaluated the effects of TET on the prevention of MDR in the osteosarcoma cell line, U-2OS, and investigated the underlying mechanisms.

\section{Materials and methods}

Drugs and cell line. TET was supplied from Sigma-Aldrich (St. Louis, MO, USA). Paclitaxel, doxorubicin, vincristine, gemcitabine and methotrexate were supplied from Santa Cruz Biotechnology (Santa Cruz, CA, USA). Docetaxel and cisplatin were supplied from Sigma-Aldrich. PM-00104 was purchased by PharmaMar (Madrid, Spain). The human osteosarcoma cell line, U-2OS, was supplied from the American Type Culture Collection (ATCC, Manassas, VA, USA), cultured in RPMI-1640 supplemented with $10 \%$ fetal bovine serum (FBS) and $1 \%$ penicillin/streptomycin (both from Invitrogen Life Technologies, Carlsbad, CA, USA) in a humidified atmosphere of $5 \% \mathrm{CO}_{2}$ at $37^{\circ} \mathrm{C}$.

Development of resistant osteosarcoma cell line. In our study, the establishment of a resistant osteosarcoma cell line followed similar previously described protocols $(21,23,38)$. A paclitaxel-resistant cell line was established from the parental cell line, $\mathrm{U}-2 \mathrm{OS}$. The culture medium was supplemented with $0.0001 \mu \mathrm{M}$ paclitaxel alone, $1 \mu \mathrm{M}$ TET alone or a combination of $1 \mu \mathrm{M}$ TET and $0.0001 \mu \mathrm{M}$ paclitaxel. When the cells reached $90 \%$ confluence, they were harvested and then reseeded, and cultured in medium with an increased paclitaxel concentration. The cells were then treated with increasing concentrations of paclitaxel over a period of 6 months. Cell sublines at different selection points were stored in liquid nitrogen for further analyses.

Cell groups. The groups were divided into the control cells (U-2OS/control), cells treated with TET alone (U-2OS/ tetrandrine), 6 resistant U-2OS cell lines that developed resistance with final paclitaxel concentrations of $0.003,0.006$, $0.03,0.06,0.1,0.2 \mu \mathrm{M}$ paclitaxel, respectively (paclitaxel $_{0.003}$, paclitaxel $_{0.006}$, paclitaxel $_{0.03}$, paclitaxel $_{0.06}$, paclitaxel $_{0.1}$ and pacli$\operatorname{taxel}_{0.2}$ ) and 2 non-resistant U-2OS cell lines that were exposed to a combination of 0.003 or $0.006 \mu \mathrm{M}$ paclitaxel with $1 \mu \mathrm{M}$

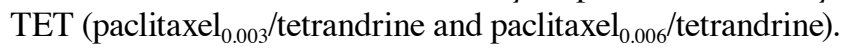

Cytotoxicity assay. The cytotoxicity of chemotherapeutic agents in the different cell sublines was evaluated by MTT assay. In brief, the cells were seeded in 96-well plates and treated with various concentrations $(0.0001,0.001,0.01,0.1$, 1,10 and $100 \mu \mathrm{M}$ ) of chemotherapeutic agents for 5 days, followed by the addition of $20 \mu \mathrm{l}$ of MTT (Sigma-Aldrich) to each well for $4 \mathrm{~h}$. The crystals were dissolved in $100 \mu \mathrm{l}$ DMSO. The absorbance at $490 \mathrm{~nm}$ was measured using a Bio-Rad microplate reader (Bio-Rad, Hercules, CA, USA). Experiments were performed in triplicate. The $\mathrm{IC}_{50}$ value was analyzed using GraphPad Prism 5 software (GraphPad Software, Inc., La Jolla, CA, USA).

Reverse transcription-quantitative PCR (RT-qPCR). The mRNA expression level of MDR1 was determined by RT-qPCR. TRIzol reagent (Invitrogen) was used to extract total RNA according to the manufacturer's instructions. The primeScript RT reagent kit (Takara, Dalian, China) was used to reverse transcribe the RNA into cDNA, then stored at $-20^{\circ} \mathrm{C}$. cDNA was amplified using a SYBR Premix Ex Taq kit (Takara) and Mx3000P instrument (Agilent Technologies, Inc., Santa Clara, CA, USA). PCR programs were carried out as follows: $95^{\circ} \mathrm{C}$ for $5 \mathrm{~min}$, followed by 30 cycles of $95^{\circ} \mathrm{C}$ for $30 \mathrm{sec}, 56^{\circ} \mathrm{C}$ for $30 \mathrm{sec}, 72^{\circ} \mathrm{C}$ for $30 \mathrm{sec}$, and a final extension for $5 \mathrm{~min}$ at $72^{\circ} \mathrm{C}$. PCR products were analyzed according to the $2^{-\Delta \Delta C t}$ method with $\beta$-actin as the standard gene.

Western blot analysis. The protein expression levels were determined by western blot analysis. Each group of cells was collected and washed with phosphate-buffered saline (PBS). The total protein extraction kit (KeyGen Biotech Co., Ltd., Nanjing, China) was used to extract the total protein according to the manufacturer's instructions. The BCA protein assay kit (KeyGen Biotech Co., Ltd.) was used to determine the protein concentrations. Briefly, an aliquot of total protein was run on SDS-PAGE and transferred onto nitrocellulose membranes (Millipore, Billerica, MA, USA), which were blocked with 5\% BSA-PBS at room temperature for $1 \mathrm{~h}$, and subsequently incubated overnight with primary antibodies against Pgp (Cat. no. HPA002199, Sigma-Aldrich), p-IкB- $\alpha$ (Cat. no. 2859S, Cell Signaling Technology, Danvers, MA, USA) or GAPDH (Cat. no. sc-20357, Santa Cruz Biotechnology) at $4^{\circ} \mathrm{C}$, respectively. To determine the NF- $\kappa B$ expression level, total nuclear protein was prepared using a commercial kit (KeyGen Biotech Co., Ltd.) according to the manufacturer's instructions. Following incubation with primary antibodies, the membranes were rinsed 3 times with PBS and anti-rabbit IgG (Cat. no. 4414, Cell Signaling Technology) and anti-mouse IgG (Cat. no. 4408, Cell Signaling Technology) were then added at a dilution of 1:10,000 followed by incubation at room temperature for $1 \mathrm{~h}$. Finally, the membranes were detected and quantified using the LI-COR Odyssey infrared imaging system and software (LI-COR Biosciences, Lincoln, NE, USA).

Rh123 accumulation assay. The different group cells were incubated at a concentration of $0.5 \mathrm{mg} / \mathrm{ml}$ fluorescent dye, Rh123 (Sigma-Aldrich) for $2 \mathrm{~h}$. The cells were harvested and washed twice with PBS, then suspended and kept in the dark. The intracellular Rh123 was determined using a flow cytometer (Becton Dickinson, San Diego, CA, USA). The data were analyzed using FlowJo 7.6.2 software (Tree Star Inc., Ashland, OR, USA).

Dual-luciferase reporter assay. The promoter activity was determined by a dual-luciferase reporter assay. Plasmid preparation was performed as previously described (39). The cells were plated in 24-well plates overnight. Using Lipofectamine 2000 according to the instructions provided by the manufacturer (Invitrogen), the cells were co-transfected transiently with an hMDR1-Luc or NF-kB-Luc construct and 
pRL-SV plasmid (Renilla luciferase expression for normalization) (Promega, Madison, WI, USA). Luciferase activity in the cell lysates was measured using a dual-luciferase reporter assay kit (Promega).

$N F-\kappa B$ DNA-binding activity assay. The DNA-binding activity was determined by electrophoretic mobility shift assay (EMSA), as previously described (37). The concentration of the nuclear protein of cells from different cell sublines was quantified by BCA assay. Equal amounts of nuclear protein $(2 \mu \mathrm{l})$ were mixed with P-labeled NF- $\kappa \mathrm{B}$ binding probe $(1 \mu \mathrm{l})$, nuclease-free water $(5 \mu \mathrm{l})$ and EMSA/gel-shift binding buffer (5X; $2 \mu \mathrm{l})$. The mixture was incubated at room temperature for $20 \mathrm{~min}$. The samples were separated by non-denaturing PAGE. The gels were dried and kept in an exposure cassette for $72 \mathrm{~h}$ at $-70^{\circ} \mathrm{C}$ for autoradiography.

The binding ability of $\mathrm{NF}-\kappa \mathrm{B}$ to the MDRI gene promoter. The binding ability was determined by chromatin immunoprecipitation (ChIP) as described in a previous study (37). A commercially available ChIP assay kit (Upstate Biotechnology, Inc., Lake Placid, NY, USA) was used according to the instructions provided by the manufacturer. Briefly, $7 \times 10^{7}$ cells in 4 different groups (U-2OS/control, U-2OS/tetrandrine, paclitaxel ${ }_{0.2}$ and paclitaxel $\mathrm{l}_{0.006}$ /tetrandrine) were used. The chromatin fraction was immunoprecipitated with an anti-NF- $\mathrm{KB}$ p65 antibody (Cat. no. 06-418, Upstate Biotechnology, Inc.) overnight at $4^{\circ} \mathrm{C}$ and finally examined by PCR.

Statistical analysis. Statistical analysis was carried out using GraphPad Prism 5 software (GraphPad Software, Inc.). The data in our study are presented as the means \pm SD. A value of $\mathrm{P}<0.05$ was considered to indicate a statistically significant difference.

\section{Results}

Tetrandrine prevents the emergence of paclitaxel resistance in the osteosarcoma cell line, $U-2 O S$. The U-2OS cells were treated with increasing concentrations of paclitaxel alone or a combination of paclitaxel with $1 \mu \mathrm{M}$ TET. After 6 months of drug treatment, the cells treated with paclitaxel alone exhibited stable growth in the culture medium with $0.2 \mu \mathrm{M}$ paclitaxel. By contrast, the cells treated with the paclitaxel-TET combination were not able to grow when treated with paclitaxel at concentrations $>0.006 \mu \mathrm{M}$ in the culture medium (Fig. 1A). The $\mathrm{IC}_{50}$ value of paclitaxel was then evaluated to further confirm the effects of TET on paclitaxel resistance. As shown in Fig. 1B, the $\mathrm{IC}_{50}$ value of paclitaxel in the cells treated with paclitaxel alone increased as the concentration of paclitaxel increased. In addition, the $\mathrm{IC}_{50}$ value of the U-2OS cells treated with $\geq 0.03 \mu \mathrm{M}$ paclitaxel alone was significantly increased compared with the control cells. An enhancement of 64-fold in the $\mathrm{IC}_{50}$ value of paclitaxel was observed in the cells treated with $0.2 \mu \mathrm{M}$ paclitaxel alone ( paclitaxel $_{0.2}$ ) compared with the control cells. However, the cells treated with the $0.006 \mu \mathrm{M}$ paclitaxel-TET combination (paclitaxel $\mathrm{p}_{0.006} / \mathrm{TET}$ ) exhibited no obvious increase in the $\mathrm{IC}_{50}$ value of paclitaxel compared with the control cells. Notably, the $\mathrm{IC}_{50}$ value of paclitaxel in the paclitaxel $l_{0.2}$ cells was 53.3 -fold higher than that of the paclitaxel $_{0.006} /$ TET cells, demonstrating that TET inhibited the initiation of paclitaxel resistance in the osteosarcoma cell line, $\mathrm{U}-2 \mathrm{OS}$. There was no change in the $\mathrm{IC}_{50}$ value of paclitaxel in the cells treated with $1 \mu \mathrm{M}$ TET alone (Fig. 1B).

Tetrandrine inhibits the development of MDR in cells treated with paclitaxel and different chemotherapeutic agents. As shown above, TET inhibited the development of paclitaxel resistance. Thus, we further investigated whether TET inhibits resistance to other chemotherapeutic drugs. Compared with the control cells, the $\mathrm{IC}_{50}$ value of doxorubicin, docetaxel and vincristine increased 30-, 16.7- and 8-fold in the paclitaxel $\mathrm{l}_{0.2}$ cells, respectively. By contrast, thne paclitaxel ${ }_{0.006} /$ TET cells remained sensitive to these 3 agents and no significant differences in the $\mathrm{IC}_{50}$ values were observed (Fig. 2B, C and D). Apart from doxorubicin, docetaxel and vincristine, the $\mathrm{IC}_{50}$ values of other Pgp substrate drugs, such as PM-00104 and gemcitabine, were also significantly increased in the paclitaxel ${ }_{0.2}$ cells. As expected, the paclitaxel ${ }_{0.006} /$ TET cells remained sensitive to PM-00104 and gemcitabine (Fig. 2E and F). Thus, our data indicate that the cells treated with paclitaxel alone naturally developed MDR, whereas the cells treated with the paclitaxelTET combination did not acquire MDR. Taken together, these results demonstrate that TET was able to inhibit the initiation of MDR in U-2OS cells during continued paclitaxel treatment. Furthermore, the $\mathrm{IC}_{50}$ values of cisplatin and methotrexate (Fig. 2G and H), which are not Pgp substrates, exhibited no significant differences between the paclitaxel $\mathrm{l}_{0.006}$ TET and paclitaxel ${ }_{0.2}$ cells, suggesting that TET may specifically suppress the development of Pgp-mediated MDR during paclitaxel treatment.

Tetrandrine prevents the development of MDR by inhibiting MDRI and Pgp. The expression levels of MDR1 and Pgp were examined to investigate the underlying mechanisms responsible for the inhibitory effects of TET on the development of MDR. The results of RT-qPCR revealed that as paclitaxel treatment continued, an obvious stepwise increase in MDR1 expression was observed in the cells treated with paclitaxel alone. However, there was a marked reduction in MDR1 expression in the paclitaxel $0_{0.006} /$ TET cells compared to the paclitaxel $\mathrm{l}_{0.2}$ cells, which indicated that TET prevented MDR1 overexpression during paclitaxel treatment (Fig. 3A and C). The results of western blot analysis revealed that the Pgp expression levels in the cells treated with $\geq 0.03 \mu \mathrm{M}$ paclitaxel alone were significantly increased compared with those of the control cells. Additionally, the increased Pgp expression levels exhibited a strong correlation with the increased paclitaxel concentration. However, Pgp overexpression was not detected in the cells treated with the paclitaxel-TET combination (Fig. 3B and D), which suggested that TET prevented the initiation of MDR in osteosarcoma by suppressing Pgp overexpression. These results indicated that culture of the cells with paclitaxel alone induced MDR1 and Pgp overexpression, which were responsible for the development of MDR. No significant differences in MDR1 and Pgp expression levels were detected in the cells cultured with the paclitaxel-TET combination compared to the control group. Taken together, our data indicated that TET prevented the emergence of MDR in the U-2OS cells by preventing the overexpression of MDR1 and Pgp during paclitaxel treatment. 

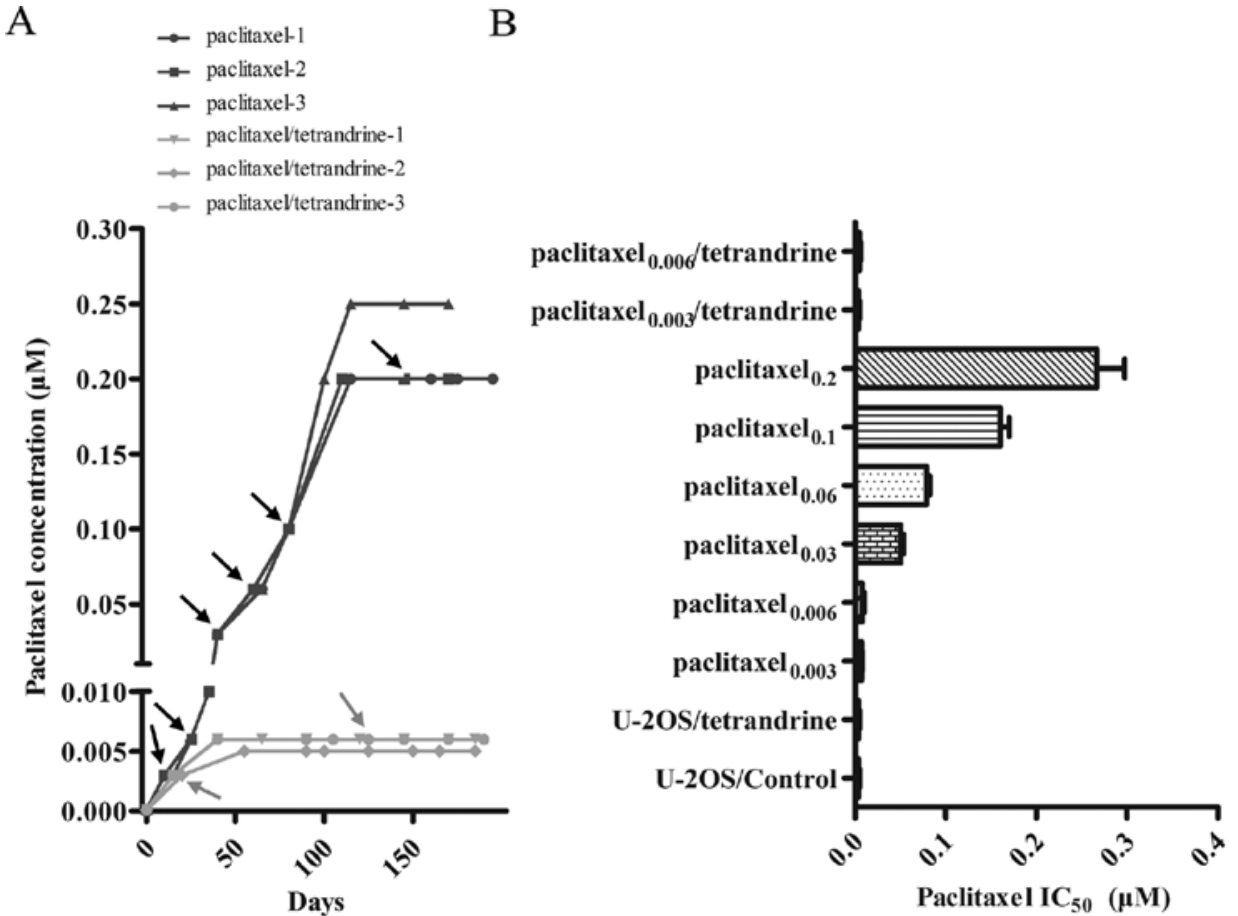

Figure 1. Tetrandrine (TET) prevents the initiation of paclitaxel resistance in the U-2OS cell line. (A) The time course of the establishment of the paclitaxelresistant U-2OS cell line in the absence or in the presence of $1 \mu \mathrm{M}$ TET. Three independent experiments were established simultaneously in cells treated with paclitaxel alone or the paclitaxel-TET combination. Different paclitaxel concentrations indicated by arrows in the time course of paclitaxel-2 and paclitaxel/TET-1 cell sublines were used in subsequent experiments. (B) $\mathrm{IC}_{50}$ value of paclitaxel in different selected cell sublines. MTT assay was performed in the cell sublines selected at different concentrations of paclitaxel as shown by the arrows in (A). Data are presented as the means \pm SD.

A
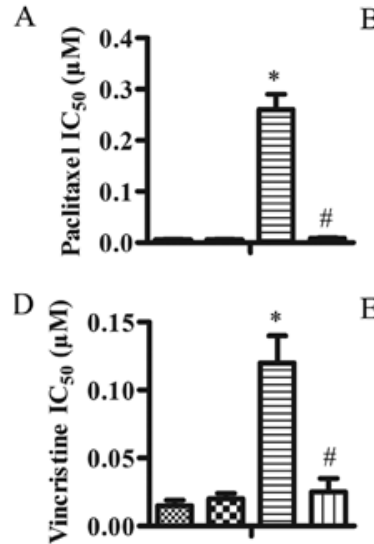

$\mathrm{B}$

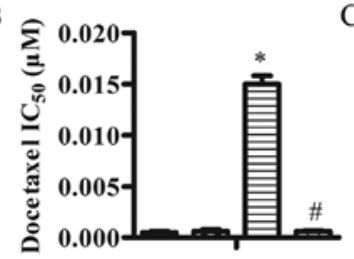

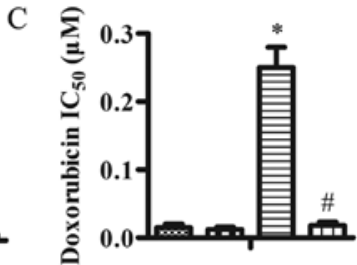
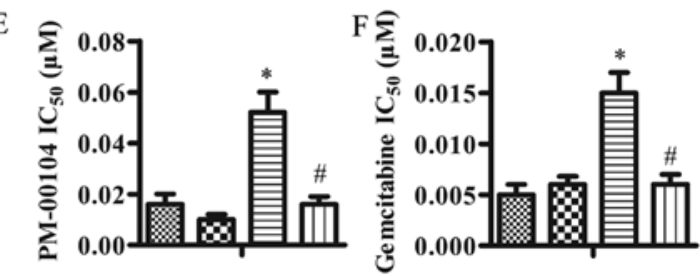

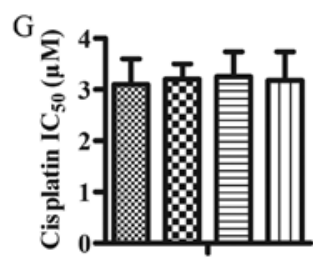

$\mathrm{H}$

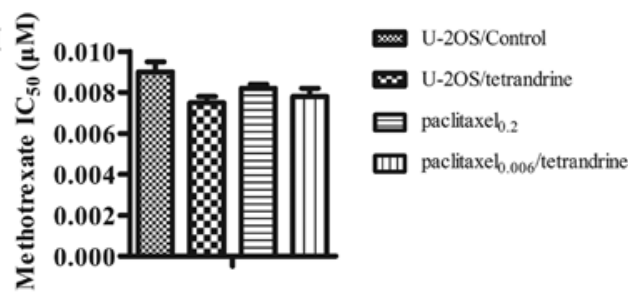

Figure 2. Tetrandrine (TET) inhibits the introduction of multidrug resistance (MDR) during continued paclitaxel treatment. MTT assay was performed in the U-2OS /control, U-2OS /TET, paclitaxel ${ }_{0.2}$ and paclitaxel $_{0.006} /$ TET cell sublines treated with different chemotherapeutic agents, including (A) paclitaxel, (B) docetaxel, (C) doxorubicin, (D) vincristine, (E) PM-00104, (F) gemcitabine, (G) cisplatin and (H) methotrexate. Data are presented as the means \pm SD. ${ }^{\text {"P }}<0.05$ vs. $\mathrm{U}-2 \mathrm{OS} /$ control group, ${ }^{\sharp} \mathrm{P}<0.05$ vs. paclitaxel $_{0.2}$ group.

Treatment of the cells with $1 \mu \mathrm{M}$ TET alone had no effect on the expression of MDR1 and Pgp.

TET decreases Pgp activity, characterized by maintaining the intracellular retention of Rh123. The intracellular accumula- tion level of Rh123 was examined by flow cytometry to identify the functional activity of Pgp. Rh123 is a substrate of Pgp with yellow-green fluorophores. The lower retention of fluorescence intensity inside cells indicates a higher activity of the Pgp pump (40). As shown in Fig. 4, a considerable difference was 


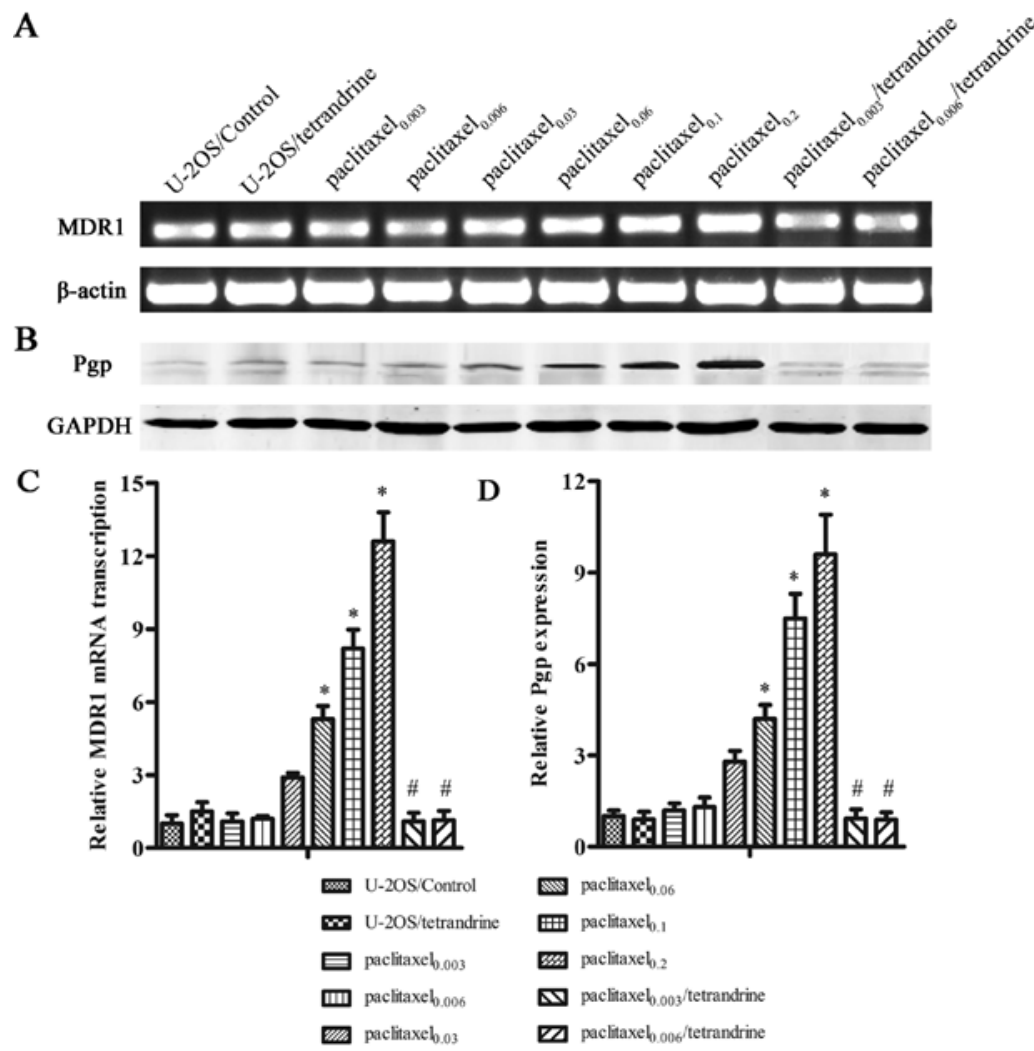

Figure 3. Tetrandrine (TET) inhibits multidrug resistance gene 1 (MDR1) and P-glycoprotein (Pgp) overexpression during paclitaxel treatment. The expression levels of MDR1 in different U-2OS cell sublines were detected by RT-qPCR. (B) Protein expression levels of Pgp were measured by western blot analysis. (C and D) Relative MDR1 and Pgp expression from (A and B) were analyzed. Data are presented as the means \pm SD. ${ }^{*} \mathrm{P}<0.05$ vs. U-2OS/control group, ${ }^{\text {"}} \mathrm{P}<0.05$ vs. paclitaxel $\mathrm{l}_{0.2}$ group.

observed between the cells cultured with the paclitaxel-TET combination and those cultured with paclitaxel alone. The fluorescence intensity of Rh123 in the paclitaxel $0_{0.2}$ group was lower compared with that in the control cells and increased significantly in the paclitaxel ${ }_{0.006} /$ TET cells as compared with the paclitaxel ${ }_{0.2}$ cells. In addition, treatment with TET alone had no obvious effect on Pgp activity. The accumulation activity of Pgp was related to the expression level of Pgp, strongly indicating that TET maintained the intracellular retention of a Pgp substrate by suppressing the overexpression of Pgp.

TET inhibits the overexpression of Pgp by inhibiting the $N F-\kappa B$ signaling pathway. A recent study found a mutation of a NF- $\kappa B$ binding site located to the MDR1 promoter (41). Furthermore, the overexpression of Pgp is regulated by the NF- $\mathrm{kB}$ signaling pathway, and thus requires a NF- $\kappa B$ binding site in the MDR1 promoter (42). To better understand the underlying mechanisms responsible for the inhibitory effect of TET on MDR, the promoter activities of MDR1 and NF- $\mathrm{KB}$ were detected by dual-luciferase reporter assay. Both MDR1 and NF- $\mathrm{KB}$ transcriptional activities were significantly increased in the paclitaxel $_{0.2}$ cells compared with the control cells. However, in the cells treated with paclitaxel $0_{0.006} / \mathrm{TET}$, these transcriptional activities were significantly inhibited and were similar to those of the control cells (Fig. 5A and B), implying that the inhibition of MDR1 activity, at least in part, may be associated with the downregulation of NF- $\mathrm{KB}$ activity. As a transcription factor, $\mathrm{NF}-\mathrm{kB}$ translocates to the nucleus to exhibit transcriptional activity. Therefore, we detected the expression of NF- $\kappa B$ in the nucleus by western blot analysis (Fig. 5C and D). Additionally, the phosphorylation of IкB- $\alpha$ is required for the activation of NF- $\kappa B$. Thus, we also assessed the $p-I_{\kappa} B-\alpha$ protein levels (Fig. 5C and E). The level of nucleic NF- $\kappa B$ was markedly upregulated in the paclitaxel ${ }_{0.2}$ cells compared to the control cells. In the paclitaxel ${ }_{0.006} /$ TET cells, however, $\mathrm{NF}-\kappa \mathrm{B}$ protein expression was decreased compared with the paclitaxel $_{0.2}$ cells. Similar to NF- $\kappa B$, the expression of $\mathrm{p}-\mathrm{I} \kappa \mathrm{B}-\alpha$ in the paclitaxel $\mathrm{l}_{0.2}$ cells was 6.3 -fold higher compared to that of the control cells; however, there was no difference between thepaclitaxel $\mathrm{l}_{0.006} / \mathrm{TET}$ and the control cells.

To further investigate the inhibition of NF- $\kappa B$ transcriptional activity by TET, NF- $\mathrm{BB}$ DNA-binding activity was assessed by EMSA. This assay demonstrated that the NF- $\kappa B$ DNA-binding activity in the paclitaxel ${ }_{0.2}$ cells was notably enhanced as compared with that of the control cells, but was reduced in the paclitaxel $\mathrm{l}_{0.006} / \mathrm{TET}$ cells, suggesting that TET inhibited NF- $\kappa$ B DNA-binding activity, which may prevent Pgp overexpression in U-2OS cells (Fig. 5F). To verify that the inhibitory effect of TET on Pgp is regulated by NF- $\mathrm{KB}$ signaling, a ChIP assay was performed. As shown in Fig. 5G, the amplified PCR product was evident, implying that NF- $\mathrm{KB}$ was bound to the MDR 1 promoter. In the paclitaxel ${ }_{0.2}$ cells, the PCR product was markedly increased, which demonstrated that the ability of NF- $\mathrm{kB}$ binding to the MDR1 promoter was enhanced by paclitaxel treatment. By contrast, the PCR product was markedly decreased in the paclitaxel ${ }_{0.006} /$ TET cells, which indicated that TET attenuated the ability of NF- $\mathrm{KB}$ binding to the MDR1 promoter. On the whole, these data strongly 
A

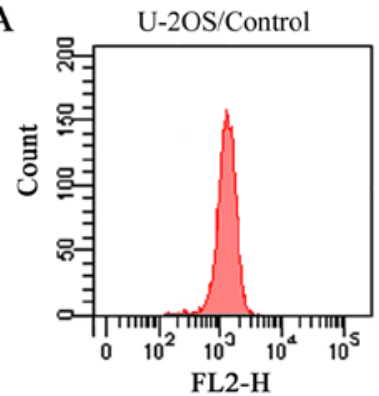

C

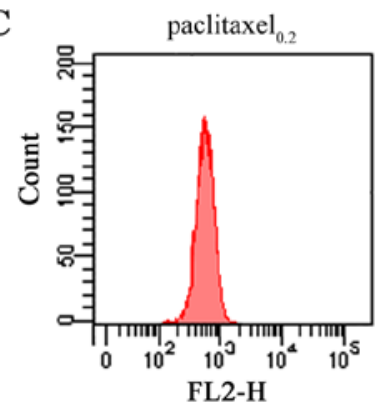

B

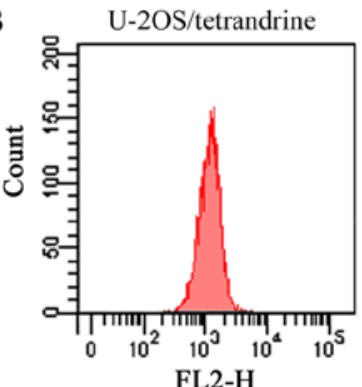

D paclitaxel $_{0.006} /$ tetrandrine

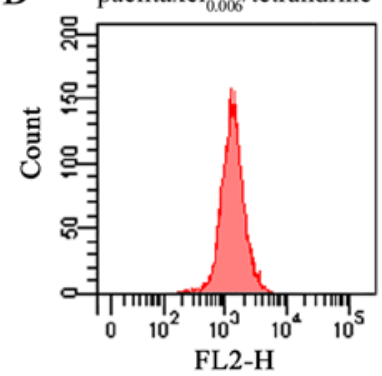

E

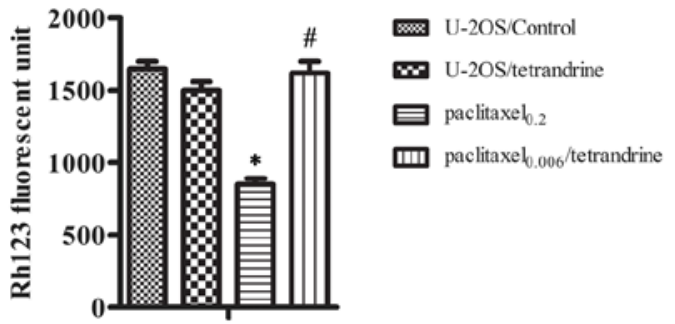

Figure 4. Tetrandrine (TET) prevents the paclitaxel-induced decrease in intracellular Rh123 accumulation. Intracellular Rh123 retention in U-2OS /control,

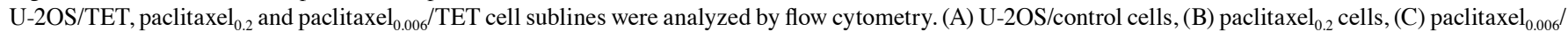
TET cells, (D) U-2OS/TET cells. (E) Relative Rh123 accumulation was analyzed. Data are presented as the means \pm SD. "P<0.05 vs. U-2OS/control group, ${ }^{\#} \mathrm{P}<0.05$ vs. paclitaxel ${ }_{0.2}$ group.

A

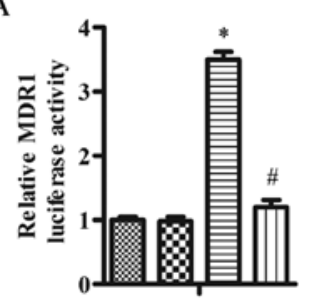

B
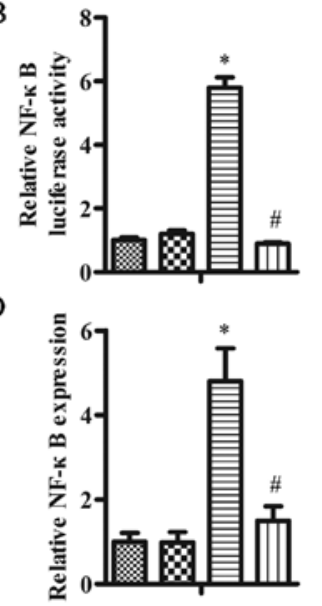

$\mathrm{E}$

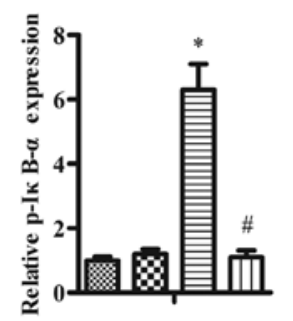

$\mathrm{C}$ NF- $\kappa B$

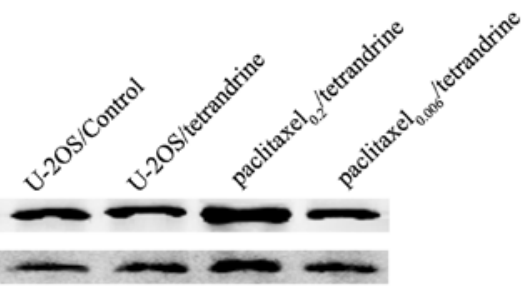

$\mathrm{F}$

GAPDH

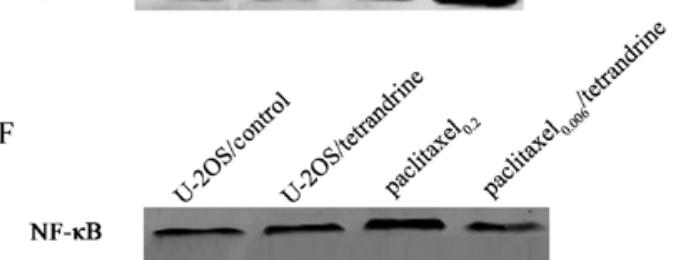

Free probes

G

NF-אB CHIP

Input

网 U-2OS/Control

U-20S/tetrandrine

曰 paclitaxe $_{0.2}$

血 paclitaxeb.006/tetrandrine

Figure 5. Tetrandrine (TET) inhibits the overexpression of P-glycoprotein (Pgp) by inhibiting NF- $\kappa$ B signaling. (A and B) Luciferase activity of multidrug resistance gene 1 (MDR1) and NF- $\kappa \mathrm{B}$ reporter genes were measured using a dual-luciferase reporter assay. (C) The expression levels of NF- $\kappa \mathrm{B}$ and $\mathrm{p}-\mathrm{I} \kappa \mathrm{B}-\alpha$ were determined by western blot analysis. (D and E) Relative NF- $\kappa$ B and $\mathrm{p}-\mathrm{I} \kappa \mathrm{B}-\alpha$ expression from (C) were analyzed. (F) NF- $\kappa \mathrm{B}$ DNA-binding activity was determined by electrophoretic mobility shift assay (EMSA). (G) NF- $\mathrm{B}$ binding ability to MDR1 promoter was determined by chromatin immunoprecipitation (ChIP). Data are presented as the means $\pm \mathrm{SD}$. ${ }^{*} \mathrm{P}<0.05$ vs. $\mathrm{U}-2 \mathrm{OS} /$ control group, ${ }^{\#} \mathrm{P}<0.05$ vs. paclitaxel 0.2 group. 
indicated that TET inhibited the overexpression of Pgp by inhibiting NF- $\mathrm{NB}$ signaling.

\section{Discussion}

Overexpression of Pgp exhibits an important function on the development of MDR $(11,12,23)$ and correlates well with an overall poor chemotherapy response and prognosis (43). Pgp acts as an energy-dependent membrane transporter, rapidly pumping out functionally and structurally unrelated chemotherapeutic drugs from cells. Inhibiting the initiation of MDR at the onset of chemotherapy may fundamentally assist in overcoming drug resistance. TET is an alkaloid isolated from the tuberous root of Stephania tetrandra. A previous study revealed that TET significantly reversed MDR in different cancer cell lines by promoting Pgp ATPase activity and suppressing Pgp function (44). Moreover, TET has been shown to prevent the leukemia cell line, K562, from developing MDR through the prevention of MDR1 transcription (37). In the present study, we established an MDR osteosarcoma cell model and demonstrated that the initiation of MDR was prevented by TET by suppressing Pgp overexpression in human osteosarcoma cells.

To establish an MDR cell line in vitro, the cells were treated with stepwise increased concentrations of paclitaxel in culture medium, which was considered the classic in vitro serial selection approach $(21,23,38)$. We successfully established the osteosarcoma MDR cell line from the drug sensitive cell line, U-2OS, using a similar procedure. The results revealed that the cells treated with paclitaxel alone acquired MDR with resistance to paclitaxel and other Pgp substrates, such as doxorubicin, docetaxel and vincristine. However, the cells treated with the paclitaxel-TET combination remained sensitive to chemotherapeutic drugs. Furthermore, the cells treated with paclitaxel alone or with the paclitaxel-TET combination did not develop drug resistance to the non-Pgp substrates cisplatin and methotrexate. These results suggest that TET may inhibit the development of MDR in osteosarcoma by inhibiting Pgp overexpression.

It has been reported that MDR can be mediated by Pgp in osteosarcoma (45). We observed that the long-term treatment of osteosarcoma cells with paclitaxel induced Pgp overexpression. The overexpression of Pgp leads to the decreased intracellular accumulation of chemotherapeutic agents, thus preventing the drugs from exerting their cytotoxic effects $(11,12,46)$. Our data demonstrated that the cells treated with paclitaxel alone exhibited reduced drug intracellular accumulation of the Pgp substrate, Rh123. In comparison, the cells treated with the paclitaxel-TET combination displayed no obvious difference with the sensitive control cells, indicating that TET allowed the retention of chemotherapeutic drugs during paclitaxel treatment. Consequently, TET enabled the osteosarcoma cells to maintain sensitivity to chemotherapeutic drugs and inhibited the introduction of MDR by preventing Pgp overexpression.

$\mathrm{NF}-\kappa \mathrm{B}$ is an important transcription factor in carcinoma. $\mathrm{NF}-\kappa \mathrm{B}$ is usually located in the cytoplasm of quiescent cells. In response to stimuli, NF- $\kappa \mathrm{B}$ isolates from its inhibitory partner $\mathrm{I} \kappa \mathrm{B}$, then translocates to the nucleus to regulate downstream genes transcription by binding to $\kappa \mathrm{B}$-binding sites. It has been reported that TET can inhibit $N F-\kappa B$ activation in various cells, such as pancreatic cells, peripheral blood $\mathrm{T}$ cells and brain cells $(47,48)$. A previous study revealed that the decreased $\mathrm{NF}-\kappa \mathrm{B}$ expression resulted in the downregulation of MDR1 and Pgp, which suggested that NF- $\kappa \mathrm{B}$ is involved in MDR regulation (49). Our results demonstrated that the cells cultured with paclitaxel alone exhibited significantly elevated promoter activities of MDR1 and NF- $\mathrm{B}$, which were significantly inhibited following paclitaxel-TET combination treatment, suggesting that TET inhibited the promoter activity of MDR1, possibly by downregulating $\mathrm{NF}-\kappa \mathrm{B}$ activity, at least in part. Subsequently, we demonstrated that the expression levels of p-I $\kappa \mathrm{B}-\alpha$ and nuclear NF- $\kappa \mathrm{B}$ were both decreased in the cells cultured with the paclitaxel-TET combination. Moreover, the NF- $\kappa \mathrm{B}$ DNA-binding activity and the ability of NF- $\kappa \mathrm{B}$ to bind to the MDR1 promoter were attenuated as compared with the cells cultured with paclitaxel alone, which suggested that TET inhibited NF- $\mathrm{NB}$ activation and subsequently regulated MDR1 gene expression. Collectively, TET inhibited the overexpression of Pgp by inhibiting NF- $\kappa$ B signaling.

In conclusion, our findings indicated that TET prevented the introduction of paclitaxel-induced MDR in osteosarcoma cells by inhibiting Pgp overexpression through a mechanism involving the inhibition of $\mathrm{NF}-\kappa \mathrm{B}$ signaling. Given its preventive effect on MDR, TET holds promise to extend the long-term efficacy of chemotherapy in patients with osteosarcoma.

\section{Acknowledgements}

The authors would sincerely like to thank the members of the Department of Orthopaedic Traumatology, Tianjin Hospital and the Department of Orthopaedics, Jixian People's Hospital for their valuable input/suggestions concerning the present manuscript.

\section{References}

1. Lin YT, Huang AC, Kuo CL, Yang JS, Lan YH, Yu CC, Huang WW and Chung JG: Induction of cell cycle arrest and apoptosis in human osteosarcoma U-2 OS cells by Solanum lyratum extracts. Nutr Cancer 65: 469-479, 2013.

2. Liang CZ, Zhang X, Li H, Tao YQ, Tao LJ, Yang ZR, Zhou XP, Shi ZL and Tao HM: Gallic acid induces the apoptosis of human osteosarcoma cells in vitro and in vivo via the regulation of mitogen-activated protein kinase pathways. Cancer Biother Radiopharm 27: 701-710, 2012.

3. Cho HJ, Lee TS, Park JB, Park KK, Choe JY, Sin DI, Park YY, Moon YS, Lee KG, Yeo JH, et al: Disulfiram suppresses invasive ability of osteosarcoma cells via the inhibition of MMP-2 and MMP-9 expression. J Biochem Mol Biol 40: 1069-1076, 2007.

4. Marina N, Gebhardt M, Teot L and Gorlick R: Biology and therapeutic advances for pediatric osteosarcoma. Oncologist 9: 422-441, 2004.

5. Chou AJ, Geller DS and Gorlick R: Therapy for osteosarcoma: where do we go from here? Paediatr Drugs 10: 315-327, 2008.

6. Chou AJ and Gorlick R: Chemotherapy resistance in osteosarcoma: current challenges and future directions. Expert Rev Anticancer Ther 6: 1075-1085, 2006.

7. Dieudonné FX, Marion A, Haÿ E, Marie PJ and Modrowski D: High Wnt signaling represses the proapoptotic proteoglycan syndecan-2 in osteosarcoma cells. Cancer Res 70: 5399-5408, 2010.

8. Wang ZY, Mei J, Gao YS, Ni M and Yao B: Primary tumorectomy promotes angiogenesis and pulmonary metastasis in osteosarcoma-bearing nude mice. Acta Cir Bras 28: 190-194, 2013.

9. Agarwal R and Kaye SB: Ovarian cancer: strategies for overcoming resistance to chemotherapy. Nat Rev Cancer 3: 502-516, 2003.

10. Glavinas H, Krajesi P, Cserepes J and Sarkadi B: The role of $\mathrm{ABC}$ transporters in drug resistance, metabolism and toxicity. Curr Drug Deliv 1: 27-42, 2004. 
11. Gottesman MM, Fojo T and Bates SE: Multidrug resistance in cancer: role of ATP-dependent transporters. Nat Rev Cancer 2: 48-58, 2002.

12. Ozben T: Mechanisms and strategies to overcome multiple drug resistance in cancer. FEBS Lett 580: 2903-2909, 2006.

13. Higgins CF: Multiple molecular mechanisms for multidrug resistance transporters. Nature 446: 749-757, 2007.

14. Bodey B, Taylor CR, Siegel SE and Kaiser HE: Immunocytochemical observation of multidrug resistance (MDR) p170 glycoprotein expression in human osteosarcoma cells. The clinical significance of MDR protein overexpression. Anticancer Res 15: 2461-2468, 1995.

15. Chano T, Mori K, Scotlandi K, Benini S, Lapucci C, Manara MC, Serra M, Picci P, Okabe H and Baldini N: Differentially expressed genes in multidrug resistant variants of U-2 OS human osteosarcoma cells. Oncol Rep 11: 1257-1263, 2004.

16. Okada T, Tanaka K, Nakatani F, Sakimura R, Matsunobu T, Li X, Hanada M, Nakamura T, Oda Y, Tsuneyoshi M and Iwamoto Y: Involvement of P-glycoprotein and MRP1 in resistance to cyclic tetrapeptide subfamily of histone deacetylase inhibitors in the drug-resistant osteosarcoma and Ewing's sarcoma cells. Int J Cancer 118: 90-97, 2006.

17. Susa M,Iyer AK, Ryu K, Choy E,Hornicek FJ,Mankin H, Milane L, Amiji MM and Duan Z: Inhibition of ABCB1 (MDR1) expression by an siRNA nanoparticulate delivery system to overcome drug resistance in osteosarcoma. PLoS One 5: e10764, 2010.

18. Pluchino KM, Hall MD, Goldsborough AS, Callaghan R and Gottesman MM: Collateral sensitivity as a strategy against cancer multidrug resistance. Drug Resist Updat 15: 98-105, 2012.

19. Shukla S, Ohnuma S and Ambudkar SV: Improving cancer chemotherapy with modulators of ABC drug transporters. Curr Drug Targets 12: 621-630, 2011.

20. Anuchapreeda S, Leechanachai P, Smith MM, Ambudkar SV and Limtrakul PN: Modulation of P-glycoprotein expression and function by curcumin in multidrug-resistant human KB cells. Biochem Pharmacol 64: 573-582, 2002.

21. Cocker HA, Tiffin N, Pritchard-Jones K, Pinkerton CR and Kelland LR: In vitro prevention of the emergence of multidrug resistance in a pediatric rhabdomyosarcoma cell line. Clin Cancer Res 7: 3193-3198, 2001.

22. Yen WC and Lamph WW: The selective retinoid $X$ receptor agonist bexarotene (LGD1069, Targretin) prevents and overcomes multidrug resistance in advanced breast carcinoma. Mol Cancer Ther 4: 824-834, 2005

23. Sharma AK, Zhang L, Li S, Kelly DL, Alakhov VY, Batrakova EV and Kabanov AV: Prevention of MDR development in leukemia cells by micelle-forming polymeric surfactant. J Control Release 131: 220-227, 2008

24. Batrakova EV, Kelly DL, Li S, Li Y, Yang Z, Xiao L, Alakhova DY, Sherman S, Alakhov VY and Kabanov AV: Alteration of genomic responses to doxorubicin and prevention of MDR in breast cancer cells by a polymer excipient: pluronic P85. Mol Pharm 3: 113-123, 2006.

25. Sarisozen C, Vural I, Levchenko T, Hincal AA and Torchilin VP PEG-PE-based micelles co-loaded with paclitaxel and cyclosporine A or loaded with paclitaxel and targeted by anticancer antibody overcome drug resistance in cancer cells. Drug Delivery 19: 169-176, 2012

26. Kolitz JE, George SL, Marcucci G, Vij R, Powell BL, Allen SL, DeAngelo DJ, Shea TC, Stock W, Baer MR, et al: P-glycoprotein inhibition using valspodar (PSC-833) does not improve outcomes for patients younger than age 60 years with newly diagnosed acute myeloid leukemia: cancer and leukemia group B study 19808 . Blood 116: 1413-1421, 2010.

27. Gandhi L, Harding MW, Neubauer M, Langer CJ, Moore M, Ross HJ, Johnson BE and Lynch TJ: A phase II study of the safety and efficacy of the multidrug resistance inhibitor VX-710 combined with doxorubicin and vincristine in patients with recurrent small cell lung cancer. Cancer 109: 924-932, 2007.

28. O'Brien MM, Lacayo NJ, Lum BL, Kshirsagar S, Buck S, Ravindranath $\mathrm{Y}$, Bernstein $\mathrm{M}$, Weinstein $\mathrm{H}$, Chang $\mathrm{MN}$, Arceci RJ, et al: Phase I study of valspodar (PSC-833) with mitoxantrone and etoposide in refractory and relapsed pediatric acute leukemia: a report from the Children's Oncology Group. Pediatr Blood Cancer 54: 694-702, 2010.

29. Kelly RJ, Draper D, Chen CC, Robey RW, Figg WD, Piekarz RL, Chen X, GardnerER, Balis FM, Venkatesan AM, et al: A pharmacodynamic study of docetaxel in combination with the P-glycoprotein antagonist tariquidar (XR9576) in patients with lung, ovarian, and cervical cancer. Clin Cancer Res 17: 569-580, 2011.
30. Schiff PL Jr: Bisbenzylisoquinoline alkaloids. J Nat Prod 50: 529-599, 1987.

31. Jang BC, Lim KJ, Paik JH, Cho JW, Baek WK, Suh MH, Park JB, Kwon TK, Park JW, Kim SP, et al: Tetrandrine-induced apoptosis is mediated by activation of caspases and PKC-delta in U937 cells. Biochem Pharmacol 67: 1819-1829, 2004.

32. Meng LH, Zhang H, Hayward L, Takemura H, Shao RG and Pommier Y: Tetrandrine induces early G1 arrest in human colon carcinoma cells by down-regulating the activity and inducing the degradation of G1-S-specific cyclin-dependent kinases and by inducing p53 and p21Cip1. Cancer Res 64: 9086-9092, 2004.

33. Liu C, Gong K, Mao X and Li WL: Tetrandrine induces apoptosis by activating reactive oxygen species and repressing Akt activity in human hepatocellular carcinoma. Int J Cancer 129: 1519-1531, 2011.

34. Wan J1 Liu T, Mei L, Li J, Gong K, Yu C and Li W: Synergistic antitumour activity of sorafenib in combination with tetrandrine is mediated by reactive oxygen species (ROS)/Akt signaling. Br J Cancer 109: 342-350, 2013

35. Ao Z and Xia W: Reversal of daunorubicin resistance by tetrandrine in leukemic cells. Zhonghua Xue Ye Xue Za Zhi 16: 235-238, 1995.

36. Wei N, Sun H, Wang F and Liu G: H1, a novel derivative of tetrandrine reverse $\mathrm{P}$-glycoprotein-mediated multidrug resistance by inhibiting transport function and expression of P-glycoprotein. Cancer Chemother Pharmacol 67: 1017-1025, 2011.

37. Shen H, Xu W, Chen Q, Wu Z, Tang H and Wang F: Tetrandrine prevents acquired drug resistance of K562 cells through inhibition of mdr1 gene transcription. J Cancer Res Clin Oncol 136 659-665, 2010.

38. Yang X, Yang P, Shen J, Osaka E, Choy E, Cote G, Harmon D, Zhang Z, Mankin H, Hornicek FJ and Duan Z: Prevention of multidrug resistance (MDR) in osteosarcoma by NSC23925. Br J Cancer 110: 2896-2904, 2014

39. Wang L, Meng Q, Wang C, Liu Q, Peng J, Huo X, Sun H, Ma X and Liu K: Dioscin restores the activity of the anticancer agent adriamycin in multidrug-resistant human leukemia K562/adriamycin cells by down-regulating MDR1 via a mechanism involving NF-kB signaling inhibition. J Nat Prod 76: 909-914, 2013.

40. Chiu LY, Ko JL, Lee YJ, Yang TY, Tee YT and Sheu GT: L-type calcium channel blockers reverse docetaxel and vincristine-induced multidrug resistance independent of ABCB1 expression in human lung cancer cell lines. Toxicol Lett 192: 408-418, 2010.

41. Sun J, Yeung CA, Co NN, Tsang TY, Yau E, Luo K, Wu P, Wa JC, Fung KP, Kwok TT and Liu F: Clitocine reversal of P-glycoprotein associated multi-drug resistance through downregulation of transcription factor $\mathrm{NF}-\kappa \mathrm{B}$ in $\mathrm{R}-\mathrm{HepG} 2$ cell line. PLoS One 7: e40720, 2012.

42. Kuo MT, Liu Z, Wei Y, Lin-Lee YC, Tatebe S, Mills GB and Unate $\mathrm{H}$ : Induction of human MDR1 gene expression by 2-acetylaminofluorene is mediated by effectors of the phosphoinositide 3-kinase pathway that activate NF-kappaB signaling. Oncogene 21: 1945-1954, 2002.

43. Leonard GD, Fojo T and Bates SE: The role of ABC transporters in clinical practice. Oncologist 8: 411-424, 2003.

44. Susa M, Choy E, Yang C, Schwab J, Mankin H, Hornicek F and Duan Z: Multidrug resistance reversal agent, NSC77037, identified with a cell-based screening assay. J Biomol Screen 15: 287-296, 2010.

45. Suto R, Abe Y, Nakamura M, Ohnishi Y, Yoshimura M, Lee YH, Imanishi T, Yamazaki H, Kijima H, Tokunaga T, et al: Multidrug resistance mediated by overexpression of P-glycoprotein in human osteosarcoma in vivo. Int J Oncol 12: 287-291, 1998.

46. Szakács G, Paterson JK, Ludwig JA, Booth-Genthe C and Gottesman MM: Targeting multidrug resistance in cancer. Nat Rev Drug Discov 5: 219-234, 2006.

47. Zhang H, Li YY and Wu XZ: Effect of Tetrandrine on LPS-induced NF-kappaB activation in isolated pancreatic acinar cells of rat. World J Gastroenterol 12: 4232-4236, 2006

48. Ho LJ, Juan TY, Chao P, Wu WL, Chang DM, Chang SY and Lai JH: Plant alkaloid tetrandrine downregulates IkappaBalpha kinases-IkappaBalpha-NF-kappaB signaling pathway in human peripheral blood T cell. Br J Pharmacol 143: 919-927, 2004.

49. Bentires-Alj M, Barbu V, Fillet M, Chariot A, Relic B, Jacobs N, Gielen J, Merville MP and Bours V: NF-kappaB transcription factor induces drug resistance through MDR1 expression in cancer cells. Oncogene 22: 90-97, 2003. 